\title{
An Investigation into Metallic Potentials in Meshkin Shahr Based on Geochemistry
}

\author{
Ehsan Ghadami, Afshin Shaham \\ Department of Mining Engineering, Islamic Azad University, South Tehran Branch, Tehran, Iran \\ Email: ehsan.ghadami@chmail.ir, afshin.shaham@chmail.ir
}

How to cite this paper: Ghadami, E. and Shaham, A. (2017) An Investigation into Metallic Potentials in Meshkin Shahr Based on Geochemistry. Open Journal of Geology, 7, 1425-1434.

https://doi.org/10.4236/ojg.2017.79094

Received: November 28, 2016

Accepted: September 17, 2017

Published: September 20, 2017

Copyright (c) 2017 by authors and Scientific Research Publishing Inc. This work is licensed under the Creative Commons Attribution International License (CC BY 4.0).

http://creativecommons.org/licenses/by/4.0/

\section{(c) (i) Open Access}

\begin{abstract}
The explosion area of Meshkin Shahr is about 2100 square meters and its mineral site is located in the heights of 2650 meters in Sabalan mountains. This site is situated between Meshkin Shahr and Sabalan villages at about 45 kilometers of the south of Sabalan. In 2009, several geochemical investigations were conducted into this site. The area is covered with volcanites and Eocene sediments which have been interrupted by the intrusions of granodiorite and daciteoids. Volcanites and intrusive rocks have been altered in a zone of about 2 square kilometers. The alteration is more of argillic, silicified and sericite variations, but its severity is extremely diverse. The most severe alteration is observed in the central parts of this zone. Furthermore, limonitization is relatively seen in a wide area of this zone in the figure of veinlets and colonization indicating sulfide mineralization underneath the weathering zone. Secondary minerals are rarely found.
\end{abstract}

\section{Keywords}

Economic Geology, Meshkin Shahr, Sabalan Mountains, Porphyry Copper, Metallic Mineral Potential, Geochemistry

\section{Introduction}

The investigation into Meshkin Shahr area can be divided into two parts. The first part is related to the geology of the area while the other deals with the economic geology surveys. Research in both parts of the project was conducted on the scale of 1:25,000. Since almost all the intended area is mountainous, elevation properties of this area matter. The properties of this area conform to a large extent to the ingredients of rocks, faults, folds, height and natural slope of land. The dominant lithology of the heights is along a variety of igneous and pyroclastic rocks. Erosive blades, cliff erosion and fault, debris cones, valleys with hard 
floor, relatively high rock surfaces, medium height rock surfaces, landforms and the prevailing morphology of this area of mountains were all studied. The most important cause of deformation is the tectonics and heterogeneity of surface rocks in this area [1].

\section{Lithology (Petrography)}

The lithology of Meshkin Shahr is divided into four parts from the center outwards. The first part of central volcanic-sub-volcanic rocks has acidic and intermediate compounds. Its most important constituents include rhyodacite, dacite, andesite basalt and acidic tuffs. The prominent property of this part is the severe alteration of rocks (Figure 1). The second part is mainly composed of extrusive igneous output and it is named volcanic ring because it surrounds the first part as a ring. The most outcropping rocks in this part are andesite basalt, pyroxene andesite, trachyandesite, trachydacite and andesitic lavas. The third part which is the outermost part of the area consists of extremely thick clastic

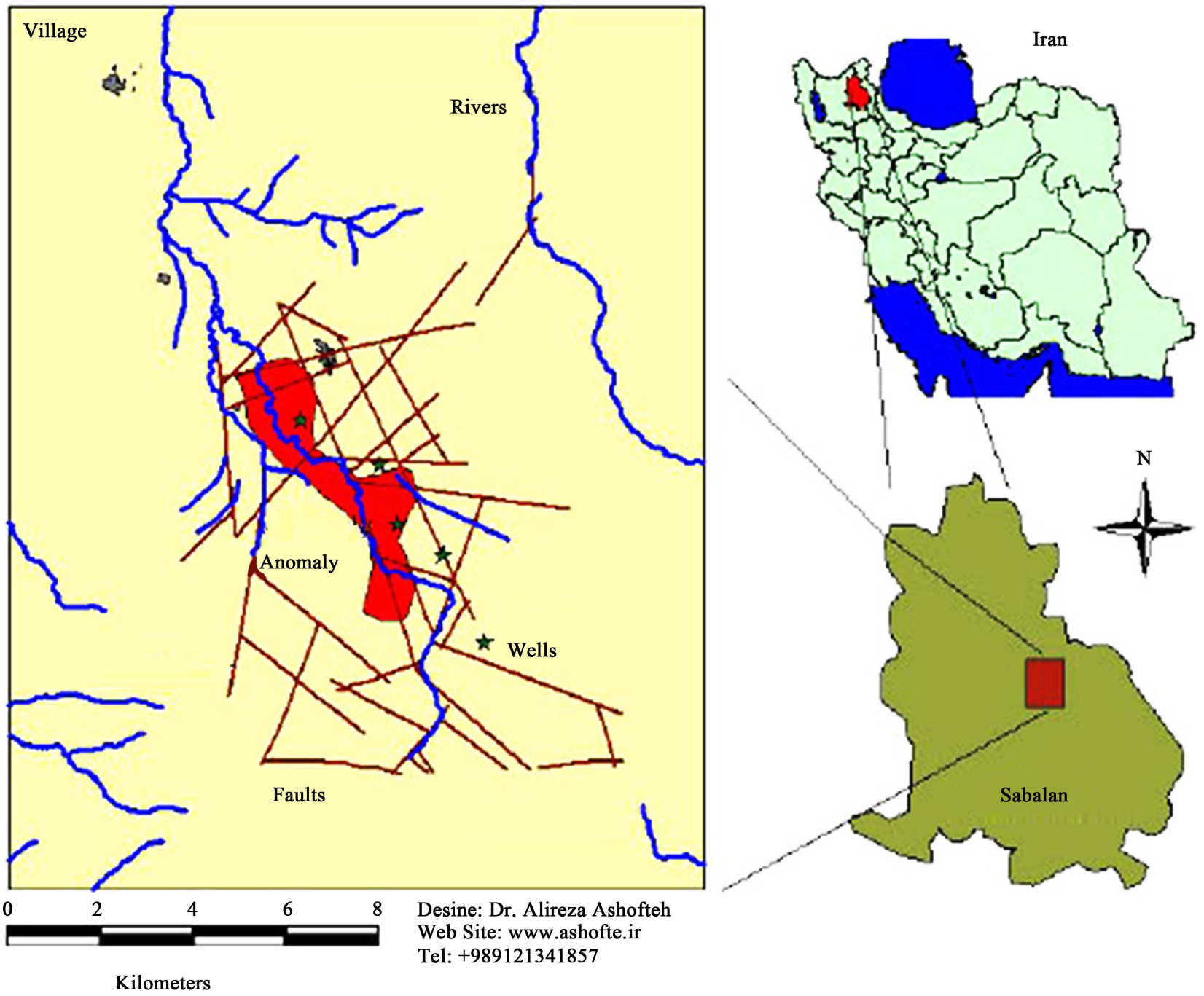

Figure 1. Map of access roads to Meshkin Shahr. 
deposits which although are made of igneous rocks, whose proportion is more exotic than the constituent rocks of Meshkin Shahr in terms of lithology, they clearly show the properties of sedimentary rocks and deposits such as layering, gradual layering, diagonal and rounded stratification and sorting (Figure 2). The thickness of these deposits sometimes exceeds 150 meters. The general slope of these deposits is formed from the center outwards at each side of this outcropping area. The fourth part is composed of dikes and tiny intrusive apophysis which are widespread all over Meshkin Shahr. A majority of the lithological composition of this group contains more varieties of diverse rocks including granodiorite, porphyry granodiorite, quartz diorite, quartz monzodiorite, diorite, rhyodacite, dacite, quartz dacite and diorite [2].

\section{Magmatism}

\section{1) Deep Semi Precious Diorite Stones}

These stones are located at the end of Pliocene and may interrupt the youngest magmatic phase of semi deep volcanic stones in Meshkin Shahr on which it is situated as a cap.

2) Dikes and Floods

Abundant dikes and floods have cut the older stones in a chaotic manner. The chemical compounds of these stones vary from dacite to diorite. Andesitic trachydikes ( $\mathrm{Tr}$ ) which permeate into a single unit (Pld) and severely degrade it (Sericite, Argillic, Oxide) can also be attached to the last phases of volcanism in Meshkin Shahr [3].

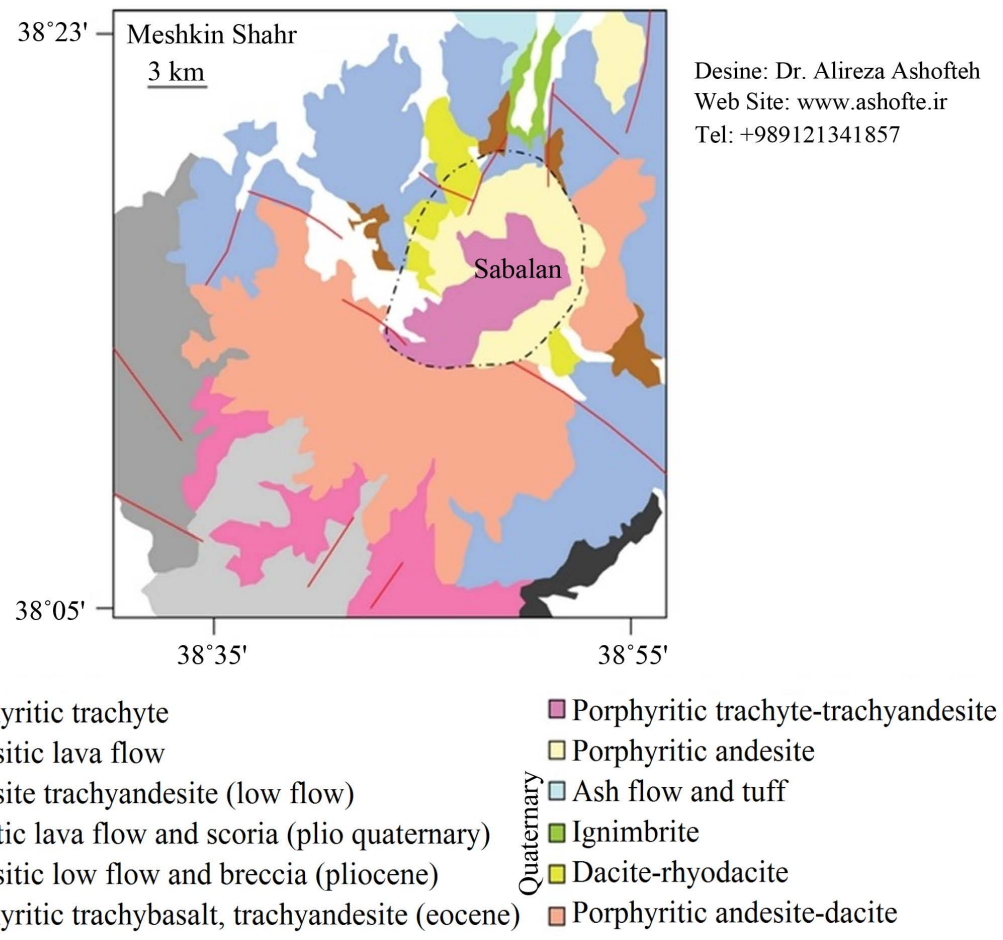

Figure 2. Map of geology the study area. 


\section{Sampling and Laboratory Studies}

The combination of data obtained from the analyses of ICP-MS, XRF, XRD, mineralography and petrography and in some cases from heavy minerals along with the information obtained from research field can help a lot in the interpretation of results. Samples collected from the intended field can be categorized into four groups.

1) Samples collected for petrological studies. These samples were used to prepare thin sections.

2) Mineralized samples or samples collected to determine their metallic minerals.

3) Samples collected for chemical analysis. The most important group of samples, which are high in number, is those selected for chemical analysis through Atomic Absorption, ICP, XRF and even more chemical methods. The most important information that can be obtained from the chemical analysis of this group of samples is the measurement of the frequency of the following 10 elements:

$\mathrm{Au}, \mathrm{Cu}, \mathrm{Zn}, \mathrm{Pb}, \mathrm{As}, \mathrm{Sb}, \mathrm{W}, \mathrm{Fe}_{2} \mathrm{O}_{3}, \mathrm{Ag}$, Mo.

4) The last group of samples is those collected for WRD examination. The main purpose of analyzing these samples is determining the quantitative values of important minerals and alteration minerals which are difficult to identify in thin sections [4].

\section{Operation Control}

The required controls have been applied to two areas. The first is quantitative data and the second is qualitative data. For the former, the devised system in this project was developed and implemented so that the maximum numerical and quantitative data are covered; such as:

1) Control of field sampling using duplicate samples,

2) Control of sample preparation workshop using bland samples,

3) Precision control of geochemical analyses using standard samples,

4) Accuracy control of geochemical analyses using replicate samples,

5) The latter, i.e., qualitative area, applies to the data obtained from the geological projects, especially mapping, which have qualitative properties [5].

\section{Estimation and Error Analysis}

There are various methods to estimate the degree of error. The most common methods of error analysis are Thampson-Howarth error analysis method as well as an analysis method known as computational method. In the computational method, the equation is assumed as

$$
e=\frac{2}{n} \sum_{i=1}^{n} \frac{\left|x_{i}-y_{i}\right|}{x_{i}+y_{i}}
$$

where: 
$n=$ The number of replicate samples,

$X_{i}$ and $Y_{i}=$ Measured values in corresponding replicate samples,

$e=$ Error percentage.

\section{Control of Replicate Samples}

Replicate errors are more appropriate for the sampling sites which can be assumed homogeneous with tolerance such as silt sampling and liquid media. Rock media cannot be assumed to possess such primary property. Even in ores like porphyry types, there are various and numerous limitations for such premises. However, despite all limitations, the collection of replicate samples from rock media can bring about an ungeneralizable, though primary, idea; particularly in Meshkin Shahr project whose sampling media were not considered mineralized in a review with a precision of $20 \times$ (Figure 3 ). The other important point about comparing the replicate samples to apply the sampler error is that the precision and accuracy of performed analyses should be at an acceptable level, i.e., more or to a least degree less than $10 \%$. It is only in $\mathrm{n}$ this case that the error of duplicate samples can be estimated. The accuracy error of analyses is mainly greater than $10 \%[6]$.

\section{Precision Assessment of Analyses Using Standard Samples}

With respect to the fact that standard samples should have an extremely exclusive condition to be used as a control sample, it is worth noting that these standard samples belong to the well-known laboratory of AMDEL. Comparing the analysis' results of these samples, one can define and obtain the confidence level of performed analyses for each element. Table 1 presents the confidence level of analyses for each element which was obtained based on the mean error of each element. According to the results, the confidence level of analyses is $92.18 \%$ and 85.72\% for $\mathrm{Au}$ and $\mathrm{Cu}$ respectively; the same order is presented in the table for

Table 1. Confidence level of analyses for each element.

\begin{tabular}{cc}
\hline Elements & Confidence level \\
\hline $\mathrm{Au}$ & $92 / 18$ \\
$\mathrm{Ag}$ & $77 / 83$ \\
$\mathrm{Cu}$ & $85 / 72$ \\
$\mathrm{Mo}$ & $64 / 09$ \\
$\mathrm{Fe}_{2} \mathrm{O}_{3}$ & $66 / 68$ \\
$\mathrm{~Pb}$ & $87 / 67$ \\
$\mathrm{Zn}$ & $84 / 82$ \\
$\mathrm{~W}$ & $85 / 85$ \\
$\mathrm{As}$ & $93 / 13$ \\
$\mathrm{Sb}$ & $81 / 21$ \\
\hline
\end{tabular}



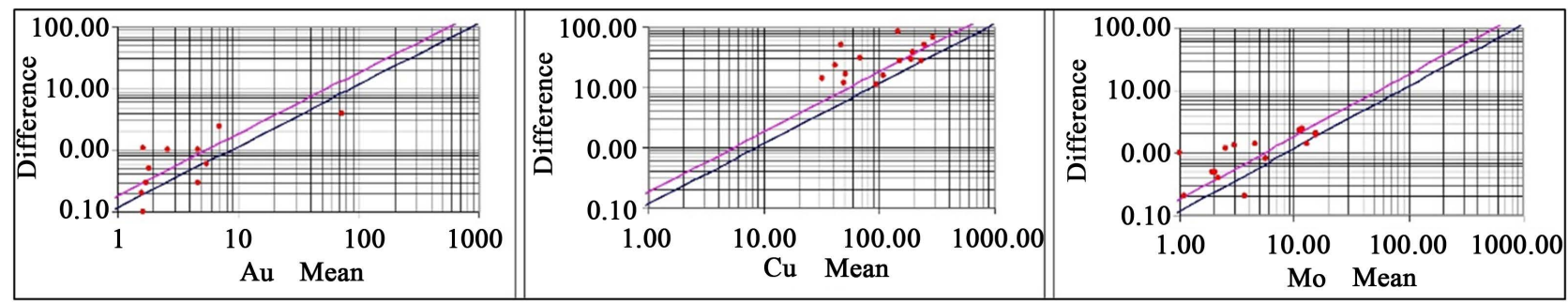

Figure 3. Diagram of errors of $\mathrm{Au}, \mathrm{Cu}$ and Mo elements.

the other elements. The acceptable values for confidence level can be determined with regard to the type of exploratory stage, sampling site, and many other factors which affect the values (Figure 4). In detailed and semi-detailed exploratory activities, the confidence level is considered to be $98 \%$ [7].

\section{Accuracy Assessment of Analyses Using Replicate Samples}

The degree of error in the analysis of pairs of replicate samples has been estimated in two separate methods. The first estimation method is Thompson-Howarth scatter plot. The results indicate that only replicate values of $\mathrm{Fe}_{2} \mathrm{O}_{3}$ are smaller than $10 \%$ while the error of other elements is higher than $10 \%$. The other common method is the computational method which is obtained by $X_{i}-Y_{i}$ divided by $X_{i}+Y_{i}$ with a coefficient of 1 due to the duplication of replicate samples. Table 2 represents the average error values of each element. As shown in Table 2 only $\mathrm{Fe}_{2} \mathrm{O}_{3}$ has a mean error of less than $10 \%$ [8].

\section{Assessment of Analyses Using Comparative Method}

Thompson-Howarth method is an appropriate method for all the samples collected from stream sediments through silt sampling and is less used for litho-geochemical samples. On the other hand, the computational method which is relatively a strict method may not be suitable for Meshkin Shahr project at this phase and is mainly used for detailed and semi-detailed phases. There is still another method which is more apt for identification activities. In this method, the observed values for the pairs of replicate samples are entered as $\mathrm{X}$ and $\mathrm{Y}$ in a simple diagram and are plotted accordingly. If the sum of all plots for each element is placed along a line or any slope it has, it is assumed that the results are unreliable. Even though this method is more comparative in which numbers are used, the byproduct is more qualitative and not quantitative. However, it is more applicable to identification operational phases at smaller scales than two aforementioned methods. Figure 3 shows the diagrams related to replicate samples. Based on the comparative method, the observed values of $\mathrm{Au}$ are scattered in replicate samples, i.e., there is significant difference between the results of primary samples and replicate samples. This is true about silver metal (Ag) when it has small amounts in samples. $\mathrm{Cu}$ has got a better status than $\mathrm{Au}$ and $\mathrm{Ag}$. For $\mathrm{Fe}_{2} \mathrm{O}_{3}$, the compared values are located on a hypothetical line as expected. This is indicative of an acceptable accuracy based on the comparison of values obtained from 

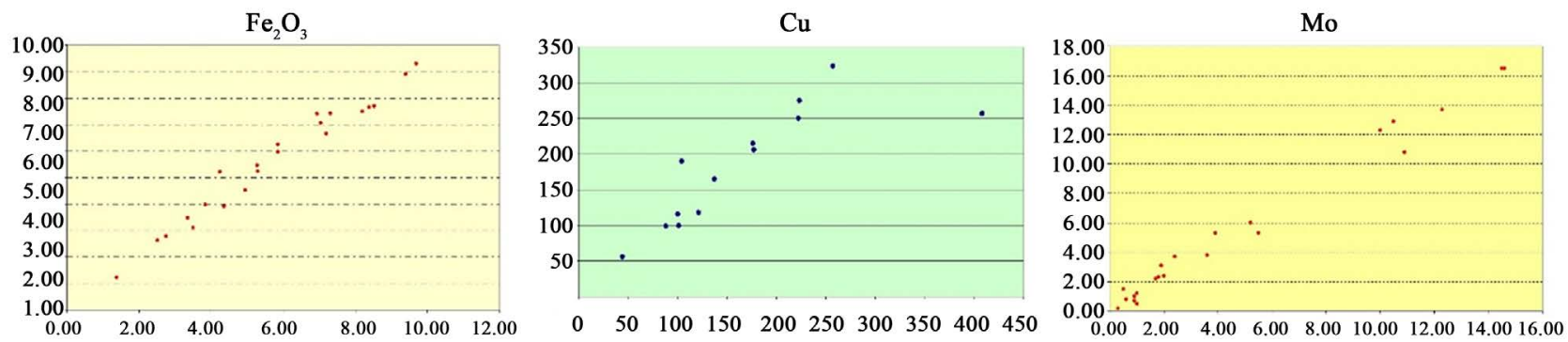

Figure 4. Comparison of the results of replicate samples.

Table 2. Values of mean error.

\begin{tabular}{cc}
\hline & Error percentage of replicate samples \\
\hline $\mathrm{Au}$ & $12 / 83$ \\
$\mathrm{Ag}$ & $33 / 46$ \\
$\mathrm{Cu}$ & $12 / 90$ \\
$\mathrm{Fe}_{2} \mathrm{O}_{3}$ & $3 / 26$ \\
$\mathrm{Mo}$ & $13 / 17$ \\
$\mathrm{~Pb}$ & $15 / 60$ \\
$\mathrm{Zn}$ & $21 / 66$ \\
$\mathrm{~W}$ & $17 / 30$ \\
$\mathrm{As}$ & $19 / 70$ \\
$\mathrm{Sb}$ & $28 / 92$ \\
\hline
\end{tabular}

replicate samples. The compared values for Mo in the aforementioned samples show a little scattering trend though not entirely. If the observed values of an element can be divided into a big and small group, it will be better to compare the observed responses once with all samples and the other time by eliminating samples with anomalous values in order to obtain more accurate results. In the diagram, the values of $\mathrm{Pb}$ are assumed to be on a single line. However, it can be induced that what has been considered as a "Proper Result" cannot, in fact, be acceptable if the anomalous value is eliminated. This example has been shown in the second diagram of $\mathrm{Pb}$ for replicate samples. Comparing the results of replicate samples for $\mathrm{Zn}$ indicates an extreme chaos in the diagram. This disorder is also evident for $\mathrm{W}$ even though it is less than Zn's disorder [9].

\section{Summary of Sample Analysis}

Meshkin Shahr's samples were analyzed for determining 10 elements $\mathrm{Zn}, \mathrm{Pb}, \mathrm{Sb}$, $\mathrm{As}, \mathrm{W}, \mathrm{Mo}, \mathrm{Ag}, \mathrm{Cu}$ and $\mathrm{Au}$. The analysis procedure included:

1) Au by emission spectrometry and atomic absorption with a limit of $0.3 \mathrm{ppb}$,

2) As and Sb by atomic fluorescence,

3) W and Mo by polarography,

4) Other elements by emission spectrometry and atomic absorption.

Sample Preparation 
To prepare the samples, each sample is first pulverized in a specialized device. Then the pulverized samples are thoroughly mixed and divided consecutively by a "divider". This process continues until the weight of each section of four parts is as much as 100 grams. Three 100 -gram parts are sent to sample archive and the other remaining part is sent to the next stage of workshop to prepare a powder. The prepared powder is sent to the laboratory for further process [10].

\section{Assessment of Geochemical Samples}

Considering litho-geochemical data related to the samples of Meshkin Shahr, it can be indicated that elements including $\mathrm{Ag}, \mathrm{Mo}, \mathrm{Pb}, \mathrm{Zn}, \mathrm{W}, \mathrm{As}$ and $\mathrm{Sb}$ are similar to enriched mineral deposits or ores and their sampling site can, indeed, be assumed mineralized. The elements of $\mathrm{Cu}$ and $\mathrm{Zn}$ can constitute a comorbid together which are separated from the comorbid of $\mathrm{Ag}, \mathrm{Pb}, \mathrm{As}, \mathrm{Sb}$ and $\mathrm{Au}$ elements. This shows that in this region, there are:

1) Either two distinct style of mineralization,

2) Or Meshkin Shahr has displayed the zoning of single mineralization style [11].

\section{Factor Analysis}

Factor analysis can be used to not only realize the dependency of elements but also identify and map the samples of different factors using factor scores. The factor analysis of Meshkin Shahr samples was done at the second phase. In the first phase, two factors were obtained, using all the elements, in one of which $\mathrm{Cu}$ and $\mathrm{Zn}$ and in the other $\mathrm{Ag}, \mathrm{Mo}, \mathrm{Pb}, \mathrm{W}$, As, and $\mathrm{Sb}$ were present. Au belonged to both factors. Therefore, the elements of $\mathrm{Au}, \mathrm{W}$ and Mo indicate a significant difference in comparison to Jacquard method. These three elements were put aside for the second stage of factor analysis [12].

\section{Results}

1) Although the confidence level of performed analyses is not high as expected, it does not imply the unreliability of their accuracy. It is quite necessary to increase the confidence level to $98 \%$ with more coordination with the laboratory in order to continue the activity in stages with larger scales in this site. This increase in confidence level is quite possible.

2) The accuracy of analyses is less than $10 \%$ except for $\mathrm{Fe}_{2} \mathrm{O}_{3}$; nevertheless, the observed error values are not generally too high to result in the unreliability of obtained numerical values. However, determining the error value of analyses for each element will help proceed further in future plans so that the next groups can achieve complete confidence and less error with the awareness of all the flaws.

3) Low confidence level as well as errors higher than $10 \%$ at this stage of exploratory activities implemented at the scale of 1:25,000 cannot be detrimental to this project because the interpretation of results at this scale in the present project is not solely dependent on analysis, i.e., there are many various factors like geol- 
ogy, ore formation, alteration, direct field observation and many other which play more crucial role in the interpretation.

4) Definitely, in the operation phases at larger scales in which the project inclines to more quantitative trend, the confidence level of $98 \%$ as well as an accuracy higher than $10 \%$ plays a vital role for analyses.

\section{Acknowledgements}

The authors thank Dr. Alireza Ashofteh for give data and for remarkable contribution of this research.

\section{References}

[1] Ashofteh, A. and Adib, A. (2014) Primitive Studies for Copper Deposit in Bidkhan Copper Mine with Regards to Wide Survey of Altered Areas and Mineral Indexes. Journal of Middle East Applied Science and Technology (JMEAST), 4, 86-90.

[2] Mohammadi, G. and Ashofteh, A. (2015) Geotechnical \& Foundation Engineering Studies of Additional Structures of Asaluyeh. Journal of Environmental Treatment Techniques (JETT), 3, 98-105.

[3] Mohammadi, G. and Ashofteh, A. (2014) Facies and Sedimentary Environment of Cretaceous Units at North West of Dihuk-Tabas Region (Shotori Mountain Range). Journal of Middle East Applied Science and Technology (JMEAST), 6, 148-152.

[4] Mohammadi, G., Gholinejad, M. and Ashofteh, A. (2013) Sedimentology and Sedimentary Environment of Mobarak Formation in Haraz Area-Mobarakabad Village, Iran. Journal of Environmental Treatment Techniques (JETT), 1, 165-167.

[5] Ashofteh, A. and Adib, A. (2015) An Investigation into the Metal Potentials across Bidkhan Area Based on Economic Geological Studies. Open Journal of Geology (OJG), 5, 727-742. https://doi.org/10.4236/ojg.2015.511064

[6] Adib, A. and Ashofteh A., (2015) Studying Petrology and Determining Tectonic Setting of Bidkhan Rocks Area Southeast of Iran, Open Journal of Geology (OJG), 5 , 677-688. https://doi.org/10.4236/ojg.2015.510060

[7] Adib, A. and Ashofteh, A. (2013) Geotechnical \& Foundation Engineering Studies of Additional Structures of Phase 12 of South Pars Gas (Tombak Region). Journal of Basic and Applied Scientific Research (JBASR), 3, 662-684.

[8] Mohammadi, G. and Ashofteh, A. (2014) Determining of Source Rock and Its Characteristics Using Organic Geo-Chemistry Derived from Parent Rock Evaluation, Separation and Columnar and Gaseous Chromatography on Cretaceous Units in Central Iran at Khor-Biyabanak. European Online Journal of Natural and Social Science (EOJNSS), 3, 151-160.

[9] Mohammadi, G. and Ashofteh, A. (2014) Investigation and Usage Sedimentary and Depositioal Environment of Creataceous in South, East of Golpayegan Area. European Online Journal of Natural and Social Science (EOJNSS), 3, 179-185.

[10] Mohammadi, G., Pursafari, M. and Ashofteh, A. (2014) The Eocene-Oligocene Facieses and Sedimentary Environments in Sardarreh Area, Garmsar. European Online Journal of Natural and Social Science (EOJNSS), 3, 86-94.

[11] Mohammadi, G., Shirzad, M. and Ashofteh, A. (2015) Facies and Sedimentary Environment of the Late Cretaceous Units at Abegarm (Avaj) Area. Current World Environment an International (CWE), 10, 771-781. https://doi.org/10.12944/CWE.10.Special-Issue1.93 
[12] Mohammadi, G., Batmanghelich, E. and Ashofteh, A. (2015) Investigation of Sedimentology, Sedimentary Environment and Facies of Late Cretaceous in Farahzad Zone North of Mojenshahroud. Current World Environment an International ( $C W E$ ), 10, 1060-1071. https://doi.org/10.12944/CWE.10.Special-Issue1.126

Submit or recommend next manuscript to SCIRP and we will provide best service for you:

Accepting pre-submission inquiries through Email, Facebook, LinkedIn, Twitter, etc. A wide selection of journals (inclusive of 9 subjects, more than 200 journals)

Providing 24-hour high-quality service

User-friendly online submission system

Fair and swift peer-review system

Efficient typesetting and proofreading procedure

Display of the result of downloads and visits, as well as the number of cited articles Maximum dissemination of your research work

Submit your manuscript at: http://papersubmission.scirp.org/

Or contact ojg@scirp.org 